\title{
Behaviour and molecular identification of Anopheles malaria vectors in Jayapura district, Papua province, Indonesia
}

\author{
Brandy St. Laurent ${ }^{1 *}\left(\mathbb{D}\right.$, Sukowati Supratman ${ }^{2 \wedge}$, Puji Budi Setia Asih ${ }^{3}$, David Bretz ${ }^{1}$, John Mueller ${ }^{1}$, \\ Helen Catherine Miller ${ }^{1}$, Amirullah Baharuddin ${ }^{4}$, Shinta ${ }^{2}$, Asik Surya ${ }^{5}$, Michelle Ngai $^{1}$, Ferdinand Laihad ${ }^{6}$, \\ Din Syafruddin ${ }^{3,5}$, William A. Hawley ${ }^{7}$, Frank H. Collins ${ }^{1}$ and Neil F. Lobo ${ }^{1}$
}

\begin{abstract}
Background: Members of the Anopheles punctulatus group dominate Papua, Indonesia and Papua New Guinea (PNG), with a geographic range that extends south through Vanuatu. An. farauti and An. punctulatus are the presumed major vectors in this region. Although this group of species has been extensively studied in PNG and the southern archipelagoes within their range, their distribution, ecology and vector behaviours have not been well characterized in eastern Indonesia.

Methods: Mosquitoes were collected in five villages in Jayapura province, Papua, Indonesia using human-landing collections, animal-baited tents and backpack aspirators. Mosquitoes were morphologically typed and then molecularly distinguished based on ribosomal ITS2 sequences and tested for Plasmodium falciparum and P. vivax infection using circumsporozoite ELISA and PCR.

Results: The presence and vector status of An. farauti 4 in Papua, Indonesia is confirmed here for the first time. The data indicate that this species is entering houses at a rate that increases its potential to come into contact with humans and act as a major malaria vector. An. farauti 4 was also abundant outdoors and biting humans during early evening hours. Other species collected in this area include An. farauti 1, An. hinesorum, An. koliensis, An. punctulatus, and An. tessellatus. Proboscis morphology was highly variable within each species, lending support to the notion that this characteristic is not a reliable indicator to distinguish species within the An. punctulatus group.

Conclusions: The vector composition in Papua, Indonesia is consistent with certain northern areas of PNG, but the behaviours of anophelines sampled in this region, such as early and indoor human biting of An. farauti 4, may enable them to act as major vectors of malaria. Presumed major vectors An. farauti and An. punctulatus were not abundant among these samples. Morphological identification of anophelines in this sample was often inaccurate, highlighting the importance of using molecular analysis in conjunction with morphological investigations to update keys and training tools.
\end{abstract}

Keywords: Malaria, Anopheles, Vector ecology, Molecular tools, Indonesia

\section{Background}

The province of Papua, Indonesia has a high burden of malaria, with the highest reported malaria incidence

\footnotetext{
*Correspondence: brandyce.stlaurent@nih.gov

${ }^{1}$ Eck Institute for Global Health, University of Notre Dame, Notre Dame, IN, USA

Full list of author information is available at the end of the article
}

among Indonesia's 34 provinces. Both Plasmodium falciparum and $P$. vivax are prevalent in the province of Papua and throughout eastern Indonesia [1-3]. P. vivax, while often not a direct cause of mortality, largely contributes to the disease burden and morbidity in this region [4, 5]. The primary vectors of $P$. vivax are not well known, as mosquito surveys do not always include screening for $P$. vivax infection along with $P$. falciparum. While there 
have been many studies of the ecology of the An. punctulatus group in neighbouring Papua New Guinea (PNG), sampling of malaria vectors and characterization of their ecology and behaviour in Indonesian Papua is lacking. In particular, comprehensive morphological and molecular analysis of anophelines in this province is uncommon.

There are currently 13 recognized members of the $A n$. punctulatus group and eight recognized members of the An. farauti complex [6-8]. Only An. farauti 1 (hereafter referred to as An. farauti) and An. punctulatus are considered to be the primary malaria vectors. Some members of the An. punctulatus group can be distinguished through different morphological features, such as spotting on the palpi $[9,10]$, but the members of the $A n$. farauti complex are morphologically indistinguishable and can only be typed to species using molecular tools [11]. There is significant morphological variation within even molecularly distinct species across their geographic range. There is also phenotypic variation within this complex, such as increased saline tolerance in $A n$. farauti and An. farauti 7 and large body size in An. oreios (formerly An. farauti 6) [12-14]. An. farauti is considered anthropophilic throughout its range and can exploit slightly saline larval habitats along the coast, unlike many other members of the An. punctulatus group [15]. Since most of these species have been shown to be capable of harbouring both $P$. falciparum and $P$. vivax parasites, the primary determinate of their status as a major vector of malaria is by their tendency to bite humans indoors or near human dwellings [16]. An. farauti 4 (like most members of the An. punctulatus group) is known to be primarily outdoor-biting and outdoor-resting [17]. $A n$. farauti 4 and An. hinesorum (formerly An. farauti 2) have been found to have $P$. falciparum positivity rates comparable to An. farauti and An. punctulatus in Papua New Guinea $[17,18]$. Species within the An. punctulatus group can also act as vectors of several different types of human filariasis [19].

Current malaria control efforts in Indonesia are primarily dependent upon the widespread use of longlasting insecticide-treated bed nets (LLINs), which do not target outdoor-biting mosquito species $[6,20$, 21]. Nonetheless, Indonesia Ministry of Health statistics show a marked decline in malaria incidence consequent to LLIN distribution and improved diagnosis and malaria case management over the past several years. A high prevalence of malaria was reported in this district in 2008 [22], and in 2014 was reported to have among the highest transmission rates in Indonesia (annual parasite incidence of 172 reported cases/1000 population in 2014) (Nyoman, Kabupatan, Jayapura, pers comm). Previous mosquito surveys in Papua, Indonesia, have not distinguished between cryptic members of the An. farauti complex [23] and most vector studies in this region predate the understanding of cryptic species complexes.

It is crucial to understand the bionomic traits of each vector species throughout their geographic range to be able to implement effective malaria control and elimination efforts, particularly since many of the species in the An. punctulatus group occur sympatrically [24]. This study adds to what is known about the An. punctulatus group within Indonesia through a brief survey and characterization of Anopheles species in five villages in Jayapura Province, Papua, Indonesia. The study illustrates the limits of reliance upon morphological identifications only for vector surveys in this particularly complex region. There are implications of the results for malaria control strategies in Indonesian Papua.

\section{Methods}

\section{Site description}

Papua, Indonesia is the easternmost province of Indonesia, bordering PNG. The eastern half of the island of Papua comprises PNG, while the western half comprises the Indonesian provinces of Papua and West Papua. The Malaria Transmission Consortium (MTC) collection sites in Papua province are in a series of villages along the coast near the provincial capital city Jayapura, very near to the border of PNG. Activities in this region include fishing, subsistence farming and harvesting spices in the jungle. Houses in this area are made of bamboo or thin pieces of wood with thatched roofs, many of which are up on stilts. Few houses have metal roofs. The open construction of these houses allows for mosquito entry from the bottom, sides and top. The health system in Papua is generally weaker than in other parts of Indonesia, which impacts surveillance, monitoring and treatment of malaria. Malaria transmission in this area is stable and high $[3,25]$.

Mosquitoes were collected in five villages in Jayapura province, Papua, Indonesia during May of 2011: Demta village, Demta sub-district; Bunyom village, Nimbokrang sub-district; Kehiran village, Sentani Kota sub-district; Nolokla village, Sentani Timur (Harapan) sub-district, and Ongan Jaya village, Yapsi (Taja) sub-district (Fig. 1). The villages were spread across the district of Jayapura with Demta, Bunyom and Ongan Jaya villages being in forested areas close to rivers, while Kehiran and Nolokla villages were in agricultural areas.

\section{Mosquito collections}

Several methods were utilized to collect anophelines. Backpack aspirators [26] were utilized hourly (from 18:00 to $06: 00$ hours) for 10 min to capture mosquitoes on bushes and foliage within and surrounding housing areas. Hourly human-landing catches (HLC) were performed 


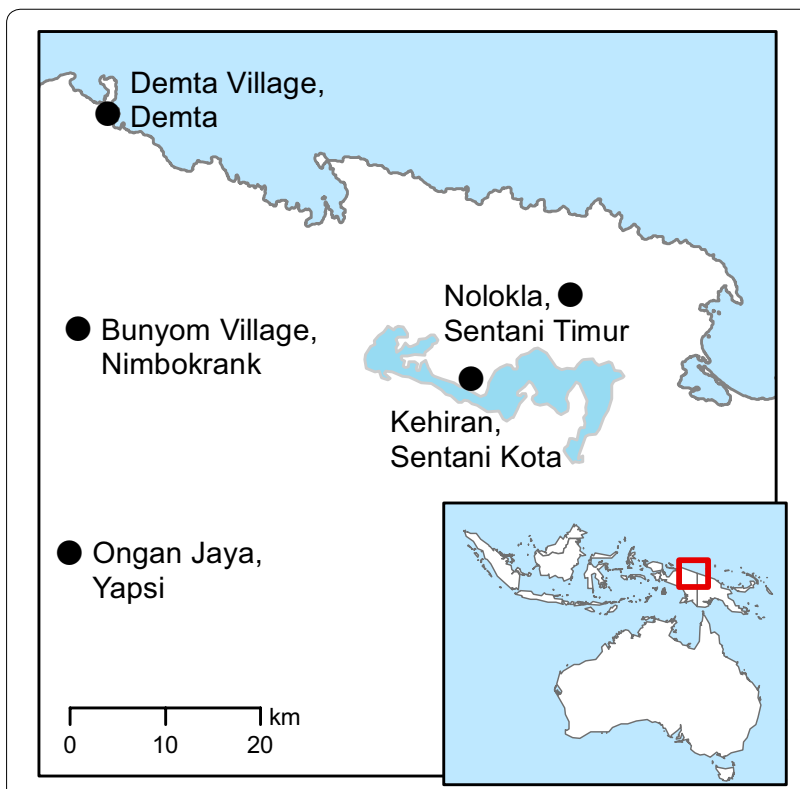

Fig. 1 Map of Jayapura field collection sites. Malaria Transmission Consortium (MTC) sites where entomological collections took place. Adult mosquitoes were collected using backpack aspirators, human landing collections, and animal-baited tents in five villages both along the coast and inland. The insert shows the field collection area in relation to the rest of Indonesia and Australia

both indoors and outdoors (from 18:00 to 06:00 hours). There were two indoor and two outdoor HLC collectors per night per site. Net tents were constructed using untreated netting with two wide openings situated around pig or cow baits. Anopheles mosquitoes were collected from the inside of the tent for ten min every hour (from 18:00 to 06:00 hours) using a mouth aspirator. The baited tents were situated away from human gathering areas and the human landing collectors. Collectors were advised not to wear any insect repellant during collections. Collections were performed for one night in each village except Kehiran, which had three nights of collections. All mosquitoes were collected, stored in holding cups labelled by hour until they were processed for morphological identification using keys for Indonesian anophelines [9]. High-quality adult specimens from the field collections were individually processed for detailed morphological descriptions of the palpi and proboscis, a key diagnostic feature of some members of the $A n$. punctulatus group.

\section{Molecular processing of samples}

Genomic DNA was isolated from individual specimens using a CTAB DNA extraction. Species were molecularly identified using sequences of the ribosomal DNA internal transcribed spacer region two (rDNA ITS2). This region of rDNA was isolated using PCR with ITS2A and
ITS2B primers [27]. The amplified fragments were purified using an enzyme clean-up: 2U of Exonuclease 1 (USB Corporation, Cleveland, $\mathrm{OH}), 1 \mathrm{U}$ of Shrimp Alkaline Phosphatase (USB), and $1.8 \mu \mathrm{l}$ of ddH20 were added to $8 \mu \mathrm{l}$ of PCR product. This mixture was incubated at $37^{\circ} \mathrm{C}$ for $15 \mathrm{~min}$, followed by $15 \mathrm{~min}$ at $80{ }^{\circ} \mathrm{C}$ to inactivate the enzymes. PCR products were sequenced directly using Sanger sequencing on ABI $3730 \mathrm{xl}$ DNA Analyzer platform (Applied Biosystems).

The ITS2 sequences were blasted against the NCBI database with BLASTn for confirmation of molecular species identification. Sequences were visually checked for sequence quality and potential contamination. Low quality or contaminated sequences were excluded from the analysis. Sequences with greater than $99 \%$ sequence identity to voucher reference sequences were confirmed as that molecular species. Voucher sequences are available in the NCBI database for the species sampled in this study. The primary PCR diagnostics for these species is also based on the sequence of the rDNA ITS2 region.

The infection status of the mosquitoes was determined using the standard CDC sandwich CS-ELISA test for the detection of $P$. falciparum, P. vivax-210, and P. vivax -247 circumsporozoite (CS) proteins [28]. A sub-set of specimens were analysed for Plasmodium infection using a multiplex PCR for P. falciparum and P. vivax [29].

Statistical analyses to evaluate indoor and outdoor biting of An. farauti 4 and An. koliensis were performed using SPSS.

\section{Results}

A total of 1071 (of 1968) individual mosquito specimens were successfully molecularly identified from Jayapura district, Papua province, Indonesia. Five morphological species were identified to six molecular species with an accuracy rate of $51 \%$ (Table 1). These molecular species include An. farauti, An. farauti 4, An. hinesorum, An. koliensis, An. punctulatus, and An. tessellatus and were determined with sequence identity, greater than $99 \%$ with reference sequences from voucher specimens.

There was a low level of accuracy when the specimens were identified morphologically in the field, with only $51 \%$ accuracy using morphology alone. The few An. farauti and An. punctulatus specimens collected were morphologically identified accurately, while three specimens of the even more distinctive An. tessellatus was identified to three different species. An. koliensis, abundant in these collections and morphologically distinguishable from the other species, was identified as An. koliensis $13 \%$ of the time. The most abundant species in the collection, An. farauti 4, was morphologically identified to An. farauti s.l. with $48 \%$ accuracy. An. koliensis may be a species complex based on rDNA ITS2 sequence variation 
Table 1 Molecular species identifications in underline with morphological species identification sub-heading by collection site

\begin{tabular}{|c|c|c|c|c|c|}
\hline \multirow{2}{*}{$\begin{array}{l}\text { Molecular spe- } \\
\text { cies ID }\end{array}$} & \multicolumn{5}{|l|}{ Village } \\
\hline & Bunyom & Demta & Kehiran & Nolokla & Ongan Jaya \\
\hline \multicolumn{6}{|l|}{ An. farauti } \\
\hline $\begin{array}{l}\text { Morph ID: An. } \\
\text { farauti s.l. }\end{array}$ & & 6 & & & \\
\hline \multicolumn{6}{|l|}{ An. farauti 4} \\
\hline $\begin{array}{l}\text { Morph ID:An. } \\
\text { punctulatus }\end{array}$ & & & 1 & & \\
\hline An. farauti s.l. & 6 & & 424 & 5 & \\
\hline An. koliensis & & & 112 & & \\
\hline An. punctulatus & 1 & & 355 & & \\
\hline \multicolumn{6}{|l|}{ An. hinesorum } \\
\hline $\begin{array}{l}\text { Morph ID: An. } \\
\text { farauti s.l. }\end{array}$ & & & & 5 & 1 \\
\hline \multicolumn{6}{|l|}{$\underline{\text { An. koliensis }}$} \\
\hline $\begin{array}{l}\text { Morph ID: An. } \\
\text { farauti s.l. }\end{array}$ & 10 & & 13 & 16 & 10 \\
\hline An. koliensis & & & 17 & 3 & \\
\hline An. longirostris & & 1 & & & \\
\hline An.punctulatus & 12 & 3 & 47 & & 16 \\
\hline An.tesselatus & & & & & 1 \\
\hline \multicolumn{6}{|l|}{ An.punctulatus } \\
\hline $\begin{array}{l}\text { Morph ID:An. } \\
\text { punctulatus }\end{array}$ & & & & & 3 \\
\hline \multicolumn{6}{|l|}{ An.tessellatus } \\
\hline $\begin{array}{l}\text { Morph ID: An. } \\
\text { farauti s.l. }\end{array}$ & & & & 1 & \\
\hline An. koliensis & & & & & 1 \\
\hline An. tesselatus & & & & & 1 \\
\hline
\end{tabular}

Molecular identification based on ITS2 sequence, compared with field morphological identifications by site. There is a low concordance of morphological to molecular-level species identifications

of samples found in other areas [18, 30], but this level of sequence variation was not observed within any of the molecularly identified specimens in this collection. These species have very similar and overlapping morphological characteristics, which can be further complicated by the quality of field-collected adult specimens. This level of accuracy in morphologically identifying field specimens when compared to molecular species identification is consistent with field collections in other areas of Southeast Asia and even countries within high transmission areas of Africa [31] (MTC data). This low level of morphological identification accuracy underlies the importance of incorporating molecular tools to help distinguish vector species.

The HLC collections indicate indoor and outdoor exposure of residents to host-seeking anophelines. Here, the majority of the species were collected both outdoors and early in the night, around dusk, at a time when people are extremely active, cooking and socializing outdoors. About 752 (74 \%) of the total 1017 specimens collected were captured before midnight, with 394 (39\%) captured before 22.00. Only 299 (29\%) were caught between midnight and 06.00 (Fig. 2). This early evening biting behaviour is consistent with observations in PNG [18]. The total Anopheles species collected were more evenly distributed through the night. The An. farauti 4 in this sample set were mostly collected in outdoor HLCs with $88 \%$ of the total An. farauti 4 collected captured in outdoor HLCs and $9 \%$ in indoor HLCs. This species may be much more prone to biting humans than was previously suspected (Fig. 3). The second-most abundant species, An. koliensis, was captured primary in indoor HLCs, 45 and $35 \%$ in outdoor HLCs. Backpack aspiration captured all six species sampled, but with relatively low numbers, and was not representative of human exposure to infectious

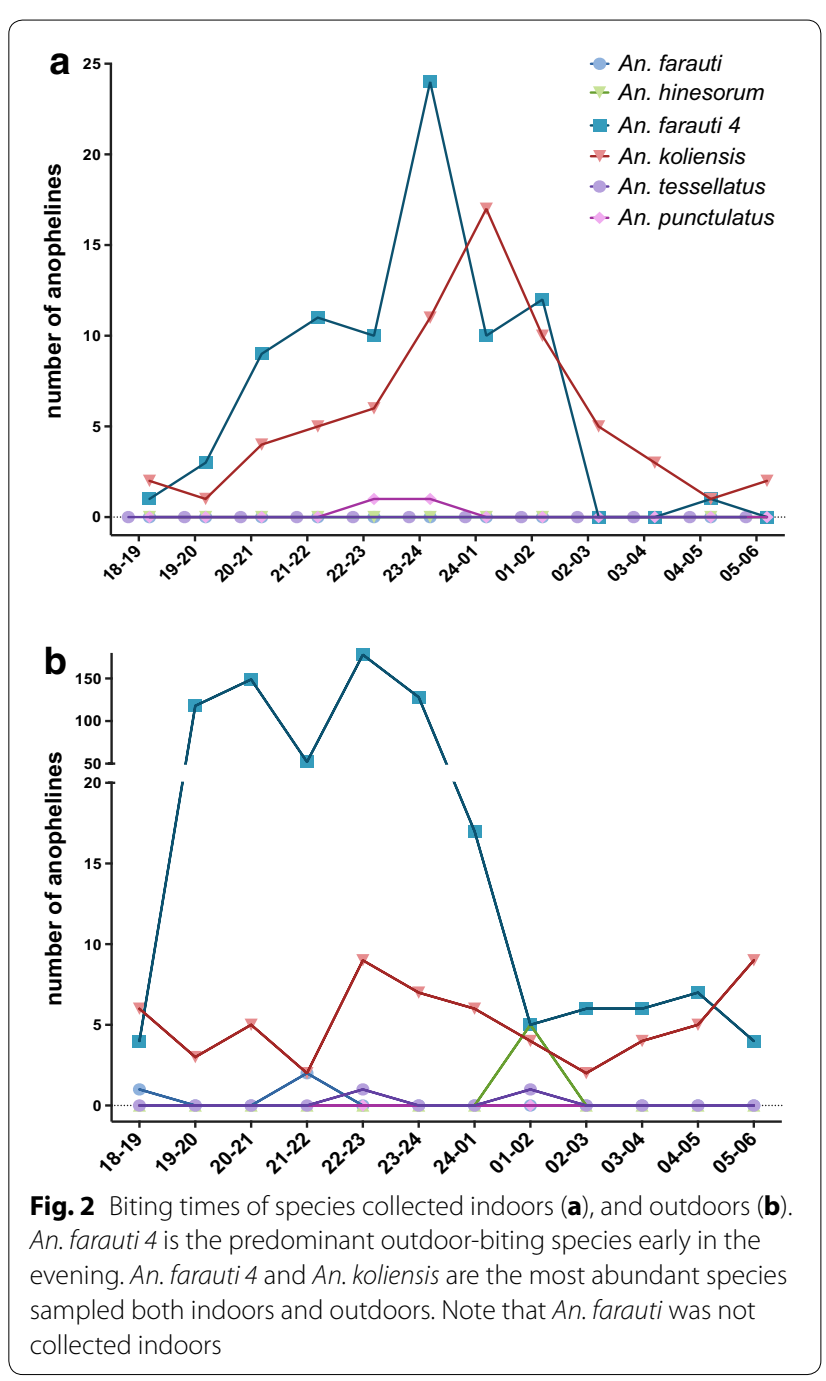




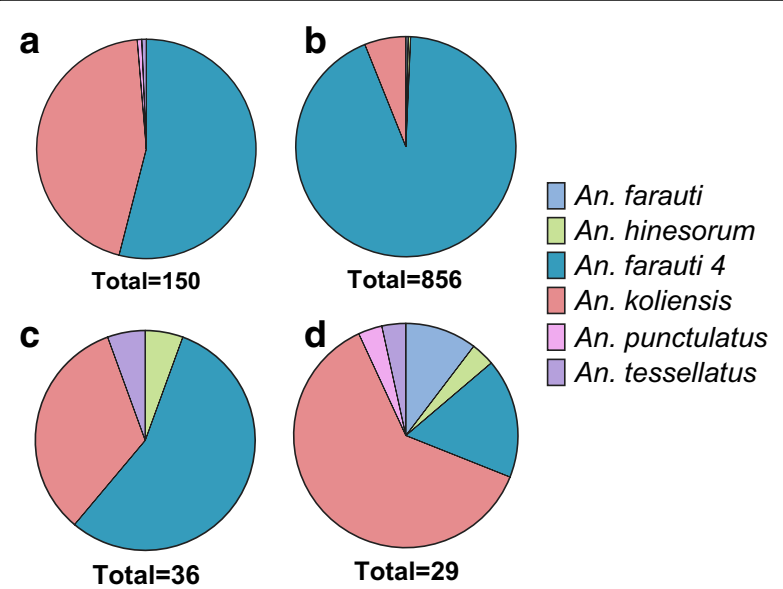

Fig. 3 Molecularly confirmed species by sampling method. a HLC indoors, b HLC outdoors, c animal-baited traps, and $\mathbf{d}$ backpack aspiration of surrounding vegetation

bites when compared to indoor or outdoor HLCs (Fig. 2). Eighty percent of all of the Anopheles samples collected in this survey were captured in outdoor HLCs.

More than half of the specimens caught in indoor and outdoor HLCs, and animal-baited traps were An. farauti 4 (Fig. 3). Fourteen percent of all of the anophelines were collected indoors, with the majority collected outdoors. An. farauti 4 was $54 \%$ of indoor HLCs, $93 \%$ of outdoor HLCs, $56 \%$ of animal-baited traps, and $17 \%$ of backpackaspirated mosquitoes from vegetation. An. koliensis was the second-most abundant species, representing 45, 6, and $33 \%$ of indoor and outdoor HLCs, and animal baited tents, respectively. An. koliensis was the most abundant species captured in vegetation, representing $62 \%$ of the catch. All other species were captured in very low abundance in each trap type. An. farauti 1 was only collected outdoors, with six specimens captured in HLC and three in vegetation (Fig. 3).

To evaluate trap efficacy for the two most prevalent species in our collections, An. farauti 4 and An. koliensis, multinomial regression was performed to compare these two species captured in indoor HLC, outdoor HLC, and backpack aspiration of surrounding foliage, which were performed every hour from 18:00 to 06:00 hours. The trap effect was not significant for An. koliensis $(p=0.021)$, and was significant for An. farauti 4 ( $p \leq 0.0001)$. An. farauti 4 was more likely to be found outdoor HLC than indoor HLC, and more likely to be caught in indoor HLC than in backpack aspiration of vegetation. A binomial logistic regression of these same two species was performed to compare their propensity to be captured indoors vs. outdoors. An. farauti 4 was 9.85 times more likely to be found outdoors than An. koliensis. Hourly biting profiles of $A n$. farauti 4 were compared using a Chi square goodness of fit test. More An. farauti 4 were caught indoors before midnight than between the hours of midnight and 6 am $\left(\chi^{2}: 15.12, d f=1, p=0.0001\right)$. The number of $A n$. farauti 4 caught indoors was significantly higher between 23 and $24 \mathrm{~h}$ when compared to other hours $\left(x^{2}=48.418\right.$; $\mathrm{df}=1, \mathrm{p}<0.0001$ ) (Additional file 1). The frequency of An. farauti 4 outdoors before midnight was higher than between the hours of midnight and 6 am $\left(X^{2}: 392.38\right.$, $\mathrm{df}=1, \mathrm{p}=<0.0001$ ).

Four of the species collected in this survey are considered to be zoophilic, An. hinesorum, An. farauti 4, An. koliensis, and An. tessellatus and they were all captured in the animal-baited tents (Fig. 3). Animal-baited tents captured only $3 \%$ of the total anophelines. Two of the four total $A n$. tessellatus samples collected were in the animal-baited tents. Only 2 and $8 \%$ of the total $A n$. farauti 4, and $A n$. koliensis specimens were captured in the animal-baited tents, with the vast majority captured in HLCs, indicating that both of these species have a higher human-biting preference than previously thought in this region. There were village-specific effects of species distribution and biting rates (Additional file 2). Futher sampling must be done to determine location-specific effects on species catch.

Human-biting rates were exceptionally high in Kehiran I village with about 84 bites per person per night outdoors and about 19 indoors. All sporozoite-positive mosquitoes were captured in this village, as were $98.7 \%$ of An. farauti 4 and $51.7 \%$ of An koliensis captured. Four individual specimens from these collections were found to be carrying $P$. vivax sporozoites, three An. farauti 4, and one An. koliensis (Table 2). In this region, An. farauti and $A n$. punctulatus are considered to be the primary vectors $[8,17,32]$. These two vector species represented a very small portion of the collection, only $0.8 \%$ of the total collection. The majority of specimens collected were An. farauti 4, representing $89 \%$ of the total collection and also found to be sporozoite positive for $P$. vivax. The three $P$. vivax-positive $A n$. farauti 4 and one $A n$. koliensis were collected in outdoor HLCs (Table 2), with 0.4 and $1.6 \%$ positivity rates, respectively.

The molecularly confirmed An. farauti 4 specimens were identified morphologically as An. punctulatus $39 \%$ of the time (Table 1). This is an issue for both species identification and the allocation of vector bionomic traits to the appropriate species. In this case, without molecular species identification, the transmission of malaria and early biting behaviour by $A n$. farauti 4 would be attributed to An. farauti s.l. and An. punctulatus. An. opheles farauti 4 is not considered to be a major malaria vector, although it has been shown to have high $P$. falciparum and $P$. vivax infection rates during mosquito surveys in 
Table 2 Individual specimens positive for Plasmodium vivax

\begin{tabular}{llllll}
\hline Molecular ID & Morphological ID & Site collected & Method of collection & Hour of collection & Method of detection \\
\hline An. farauti 4 & An. punctulatus & Kehiran & Outdoor HLC & $22-23$ & PCR \\
An. farauti 4 & An. farauti s.l. & Kehiran & Outdoor HLC & $23-24$ & ELISA PV-210 \\
An. farauti 4 & An. farauti s.l. & Kehiran & Outdoor HLC & $20-21$ & ELISA PV-210 \\
An. koliensis & An. koliensis & Kehiran & Outdoor HLC & $04-05$ & ELISA PV-210 \\
\hline
\end{tabular}

The species identification, collection information and method of Plasmodium detection are listed for individual mosquito specimens found positive for $P$. vivax. Note that An. farauti 4 and An. koliensis, two species not considered primary vectors, are positive for $P$. vivax. These four positive samples represent a $0.6 \%$. vivax positivity rate of the outdoor HLC collections in Kehiran village

Table 3 Variation of morphological proboscis phenotypes within molecular species

\begin{tabular}{|c|c|c|c|c|c|c|c|c|c|c|c|c|c|c|c|}
\hline \multirow[t]{2}{*}{ Species } & \multicolumn{15}{|c|}{ Proboscis morphology type } \\
\hline & $\mathrm{A} 1$ & B2 & B3 & $\mathrm{C3}$ & $\mathrm{C} 4$ & $\mathrm{C} 5$ & $\mathrm{C6}$ & C7 & $\mathrm{C} 8$ & $\mathrm{C} 9$ & $\mathrm{C} 10$ & $\mathrm{C} 11$ & $\mathrm{C} 12$ & C13 & C14 \\
\hline An. farauti & 6 & & & & & & & & & & & & & & \\
\hline An. farauti 4 & 408 & 85 & 188 & 2 & 66 & 15 & 1 & 4 & 16 & 25 & 11 & 63 & 2 & 10 & 4 \\
\hline An. hinesorum & 2 & 1 & & & & & & & 2 & & 1 & & & & \\
\hline An. koliensis & 12 & 80 & 4 & & 32 & & & 2 & 3 & 3 & 1 & 2 & 8 & & \\
\hline An. punctulatus & & 1 & 2 & & & & & & & & & & & & \\
\hline An. tessellatus & 2 & & & & & & & & & & & & & & \\
\hline
\end{tabular}

A1-C12 Phenotypic proboscis characteristics of the An. punctulatus group (see additional file for sketch) after Rozebloom and Knight [34] and Bryan [36]. A1 represents An. farauti and An. koliensis characteristics, B1-2 represents typically An. punctulatus features, and C phenotypes are represented within different species of the group. C13 represents a new phenotype (with a small pale spot behind labellum located in the middle of proboscis and uniform colouring of the wing sub-costa), C14 proboscis phenotypes do not fit into the other categories

PNG $[17,33]$ and has also been identified to be extremely polymorphic for proboscis characteristics which differentiate members of the An. punctulatus group [8]. Although these species have some overlapping morphological and behavioural traits, they are evolutionarily distinct [24].

Members of the An. punctulatus group have very similar morphological characteristics, often only being distinguishable by banding patterns on the underside of the proboscis, a key morphological characteristic for this group [8,9]. Even within these collections in Papua, Indonesia, additional morphological variants of these proboscis types were identified (Table 3; Additional file 3). Detailed morphology of the proboscis of individual specimens revealed morphological variation, even within cryptic species [8]. This high level of morphological variation within species has been observed elsewhere within a single cryptic species in Indonesia, such as $A n$. epiroticus and An. vagus (S Zubaidah, unpublished). The An. farauti 4 specimens in the collections were particularly morphologically variable for this trait, with specimens with each well-known phenotype, and several new phenotypes, represented within this species in the collection (Table 3; Additional file 3) [34]. An. farauti and An. punctulatus had the expected A1 and B phenotypes, respectively, while each other species had unexpected or mixed phenotypes. The assortment of proboscis phenotypes, within even cryptic species, supports the need for molecular tools to distinguish all species in the An. punctulatus group, particularly in areas where these species occur in sympatry.

\section{Conclusions}

Results of this survey illustrate the necessity for use of molecular tools to ensure accurate species identification in Indonesian Papua. Morphological identification of these specimens was wrong nearly as often it was correct, highlighting the need for supplementation of morphological keys with molecular information to allow production of better training tools for morphological identification. Morphologically based routine mosquito surveillance is needed and inevitable, but updated keys with periodic integration of molecular identification would minimize inaccuracies. There are an increasing number of species diagnostic tools that are decreasing in cost per sample, including multiplex PCRs, to identify members of the $A n$. punctulatus group. Tools such as these should be incorporated into malaria control programmes in this region to accurately identify vector species and associate them with their specific bionomic traits in order to efficiently target them, particularly in an area with such high transmission rates $[6,25,35]$. Without distinguishing fieldcollected specimens at a molecular level, the indoor and 
human-biting behaviours of An. farauti 4 and An. koliensis found in this study would have been attributed to $A n$. farauti s.l. and assumed to be An.farauti.

Although An. farauti 4 and An. koliensis were implicated as malaria vectors in this survey, it remains unclear to what extent this result can be generalized. Samples were collected in 1 month (May 2011) and nearly all of the An. farauti 4 specimens came from a single village. Although this data concludes that this species transmits malaria in Papua province, Indonesia, it is not yet know how widely distributed the species is in Indonesian Papua, or even in Jayapura district. Further studies will be needed to know if the species is seasonally abundant or regularly infected, and information on its larval habitats is lacking. It is unknown whether a change in species abundance of different anophelines may have occurred in Papua subsequent to massive scale-up of malaria control interventions targeting indoor-biting species. Such information would allow the National Malaria Control Programme to make confident inferences as to which interventions might be most effective in the future in this last redoubt of malaria in Indonesia.

\section{Additional files}

Additional file 1. The frequency of Anopheles farauti 4 mosquitoes caught outdoors. Chi square goodness of fit test of hourly biting rates of An. farauti 4. The frequency of An. farauti 4 outdoors before midnight was higher than between the hours of midnight and $6\left(x^{2}: 392.38, \mathrm{df}=1\right.$, $p \leqq 0.0001)$. Bars show differences in hourly biting where ${ }^{* * *} p<0.0001$; ${ }^{* *} p<0.001 ;{ }^{*} p<0.05$.

Additional file 2. Hourly collection of molecular species by collection method: Indoor HLC, Outdoor HLC, Animal-baited tent, and Backpack aspiration in each of 5 villages in Papua, Indonesia. *Kehiran I collections represent 3 nights of collection while all other villages took place over a single night.

Additional file 3. Variation on of morphological proboscis phenotypes of the An. punctulatus group A1-C12 Phenotypic proboscis characteristics of the An. punctulatus group adapted from Rozebloom and Knight [34] and Bryan [36] with an additional phenotype C-13.

\section{Authors' contributions}

BSTL and NFL carried out the sequence analysis, interpretation of the data, and drafted the manuscript. NFL, DS, SS, and FHC contributed to the conception and design of the study. DS, WAH, SS, PBSA, AS, FL, AB, and NFL participated in the implementation of the study and entomological collections. BSTL, PBSA, DB, JM, and HCM participated in the molecular analysis and sequence data generation. MN and NFL did the statistical analyses. All authors contributed to critical revision of the manuscript and intellectual content. All authors read and approved the final manuscript.

\section{Author details}

${ }^{1}$ Eck Institute for Global Health, University of Notre Dame, Notre Dame, IN, USA. ${ }^{2}$ National Institute of Health Research and Development, Ministry of Health, Jakarta, Indonesia. ${ }^{3}$ Eijkman Institute for Molecular Biology, Jakarta, Indonesia. ${ }^{4}$ University of Halueleo, Kendari, Indonesia. ${ }^{5}$ Department of Parasitology, Faculty of Medicine, Hasanuddin University, Makasaar 90245, Indonesia. ${ }^{6}$ National Malaria Control Programme, Ministry of Health, Jakarta, Indonesia. ${ }^{7}$ UNICEF, Jakarta, Indonesia.

\section{Acknowledgements}

This project has been funded in whole or in part by the Bill and Melinda Gates Foundation under Grant No. 45114. Special thanks to field assistants, collectors and laboratory assistants for specimen processing at the Eijkman Institute of Molecular Biology, Jakarta, Indonesia and the University of Notre Dame. Thanks to Jillian Mueller for help creating Fig. 1 and Catherine Craker for creating the proboscis phenotype additional figure. Thanks to Julie Niedbalski and Katie Cybulski for help and support at the University of Notre Dame and to Rita Kusriastuti and P R Arbani for their support.

\section{Competing interests}

The authors declare that they have no competing interests.

Received: 9 December 2015 Accepted: 15 March 2016

Published online: 08 April 2016

\section{References}

1. Arnott A, Barnadas C, Senn N, Siba P, Mueller I, Reeder JC, et al. High genetic diversity of Plasmodium vivax on the north coast of Papua New Guinea. Am J Trop Med Hyg. 2013;89:188-94.

2. Elyazar IR, Gething PW, Patil AP, Rogayah H, Sariwati E, Palupi NW, et al. Plasmodium vivax malaria endemicity in Indonesia in 2010. PLoS ONE. 2012;7:e37325.

3. Gething PW, Elyazar IR, Moyes CL, Smith DL, Battle KE, Guerra CA, et al. A long neglected world malaria map: Plasmodium vivax endemicity in 2010. PLoS Negl Trop Dis. 2012;6:e1814.

4. Douglas NM, Pontororing GJ, Lampah DA, Yeo TW, Kenangalem E, Poespoprodjo JR, et al. Mortality attributable to Plasmodium vivax malaria: a clinical audit from Papua, Indones. BMC Med. 2014;12:217.

5. Karyana M, Burdarm L, Yeung S, Kenangalem E, Wariker N, Maristela R, et al. Malaria morbidity in Papua Indonesia, an area with multidrug resistant Plasmodium vivax and Plasmodium falciparum. Malar J. 2008;7:148.

6. Beebe NW, Russell T, Burkot TR, Cooper RD. Anopheles punctulatus group: evolution, distribution, and control. Annu Rev Entomol. 2015;60:335-50.

7. Beebe NW, Cooper RD, Morrison DA, Ellis JT. Subset partitioning of the ribosomal DNA small subunit and its effects on the phylogeny of the Anopheles punctulatus group. Insect Mol Biol. 2000;9:515-20.

8. Cooper RD, Waterson DG, Frances SP, Beebe NW, Sweeney AW. Speciation and distribution of the members of the Anopheles punctulatus (Diptera: Culicidae) group in Papua New Guinea. J Med Entomol. 2002;39:16-27.

9. O'Connor CT, Soepanto A. Illustrated key to female Anophelines of Indonesia. Jakarta: Directorate of Communicable Disease, Ministry of Health; 1989.

10. Cooper RD, Waterson DG, Frances SP, Beebe NW, Sweeney AW. The anopheline fauna of Papua New Guinea. J Am Mosq Control Assoc. 2006;22:213-21.

11. Beebe NW, Cooper RD. Systematics of malaria vectors with particular reference to the Anopheles punctulatus group. Int J Parasitol. 2000;30:1-17.

12. Sweeney AW. Larval salinity tolerances of the sibling species of Anopheles farauti. J Am Mosq Control Assoc. 1987;3:589-92.

13. Bangs MJ, Taai K, Howard TM, Cook S, Harbach RE. The mosquito Anopheles (Cellia) oreios sp. n., formerly species 6 of the Australasian Anopheles farauti complex, and a critical review of its biology and relation to disease. Med Vet Entomol. 2015;29:68-81.

14. Foley $\mathrm{DH}$, Bryan JH. Shared salinity tolerance invalidates a test for the malaria vector Anopheles farauti s.s. on Guadalcanal, Solomon Islands [corrected]. Med Vet Entomol. 2000;14:450-2.

15. Beebe NW, Bakote'e B, Ellis JT, Cooper RD. Differential ecology of Anopheles punctulatus and three members of the Anopheles farauti complex of mosquitoes on Guadalcanal, Solomon Islands, identified by PCR-RFLP analysis. Med Vet Entomol. 2000;14:308-12.

16. Charlwood JD, Graves PM, Alpers MP. The ecology of the Anopheles punctulatus group of mosquitoes from Papua New Guinea: a review of recent work. P N G Med J. 1986;29:19-26.

17. Cooper RD, Waterson DG, Frances SP, Beebe NW, Pluess B, Sweeney AW. Malaria vectors of Papua New Guinea. Int J Parasitol. 2009;39:1495-501. 
18. Benet A, Mai A, Bockarie F, Lagog M, Zimmerman P, Alpers MP, et al. Polymerase chain reaction diagnosis and the changing pattern of vector ecology and malaria transmission dynamics in papua new Guinea. Am J Trop Med Hyg. 2004;71:277-84.

19. Reimer LJ, Thomsen EK, Tisch DJ, Henry-Halldin CN, Zimmerman PA, Baea $\mathrm{ME}$, et al. Insecticidal bed nets and filariasis transmission in Papua New Guinea. N Engl J Med. 2013;369:745-53.

20. Elyazar IR, Hay SI, Baird JK. Malaria distribution, prevalence, drug resistance and control in Indonesia. Adv Parasitol. 2011;74:41-175.

21. Hii JL, Smith T, Vounatsou P, Alexander N, Mai A, Ibam E, et al. Area effects of bednet use in a malaria-endemic area in Papua New Guinea. Trans $R$ Soc Trop Med Hyg. 2001;95:7-13.

22. Sorontou Y, Asih PB, Wanandi SI, Ramelan W, Syafruddin D. Malaria in Jayapura district, Papua province, Indonesia and resistance to sulfadoxine-pyrimethamine. Med J Indones. 2007;16:32-8.

23. Hii J, Smith T, Mai A, Ibam E, Alpers M. Comparison between anopheline mosquitoes (Diptera: Culicidae) caught using different methods in a malaria endemic area of Papua New Guinea. Bull Entomol Res. 2000;90:211-9.

24. Logue K, Small ST, Chan ER, Reimer L, Siba PM, Zimmerman PA, et al. Whole-genome sequencing reveals absence of recent gene flow and separate demographic histories for Anopheles punctulatus mosquitoes in Papua New Guinea. Mol Ecol. 2015;24:1263-74.

25. Elyazar IR, Gething PW, Patil AP, Rogayah H, Kusriastuti R, Wismarini DM, et al. Plasmodium falciparum malaria endemicity in Indonesia in 2010. PLoS ONE. 2011;6:e21315.

26. Vazquez-Prokopec GM, Galvin WA, Kelly R, Kitron U. A new, cost-effective, battery-powered aspirator for adult mosquito collections. J Med Entomol. 2009:46:1256-9.

27. Beebe NW, Saul A. Discrimination of all members of the Anopheles punctulatus complex by polymerase chain reaction-restriction fragment length polymorphism analysis. Am J Trop Med Hyg. 1995;53:478-81.
28. Burkot TR, Zavala F, Gwadz RW, Collins FH, Nussenzweig RS, Roberts DR. Identification of malaria-infected mosquitoes by a two-site enzymelinked immunosorbent assay. Am J Trop Med Hyg. 1984;33:227-31.

29. Singh B, Bobogare A, Cox-Singh J, Snounou G, Abdullah MS, Rahman HA. A genus- and species-specific nested polymerase chain reaction malaria detection assay for epidemiologic studies. Am J Trop Med Hyg 1999;60:687-92

30. Beebe NW, Cooper RD, Morrison DA, Ellis JT. A phylogenetic study of the Anopheles punctulatus group of malaria vectors comparing rDNA sequence alignments derived from the mitochondrial and nuclear small ribosomal subunits. Mol Phylogenet Evol. 2000;17:430-6.

31. Stevenson J, St Laurent B, Lobo NF, Cooke MK, Kahindi SC, Oriango RM, et al. Novel vectors of malaria parasites in the western highlands of Kenya. Emerg Infect Dis. 2012;18:1547-9.

32. Mueller I, Namuigi P, Kundi J, Ivivi R, Tandrapah T, Bjorge S, et al. Epidemic malaria in the highlands of Papua New Guinea. Am J Trop Med Hyg. 2005:72:554-60.

33. Charlwood JD, Birley MH, Dagoro H, Paru R, Holmes PR. Assessing survival rates of Anopheles farauti (diptera: Culicidae) from Papua New Guinea. J Anim Ecol. 1985;54:1003-16.

34. Rozeboom LE, Knight KL. The punctulatus complex of Anopheles (Diptera: Culicidae). J Parasitol. 1946;32:95-131.

35. Barcus MJ, Basri H, Picarima H, Manyakori C, Sekartuti Elyazar l, et al. Demographic risk factors for severe and fatal vivax and falciparum malaria among hospital admissions in northeastern Indonesian Papua. Am J Trop Med Hyg. 2007;77:984-91.

36. Bryan JH. Morphological studies on the Anopheles punctulatus Dönitz complex. Trans R Entomol Soc Lond. 1974;125:413-35.

\section{Submit your next manuscript to BioMed Central and we will help you at every step:}

- We accept pre-submission inquiries

- Our selector tool helps you to find the most relevant journal

- We provide round the clock customer support

- Convenient online submission

- Thorough peer review

- Inclusion in PubMed and all major indexing services

- Maximum visibility for your research

Submit your manuscript at www.biomedcentral.com/submit

() Biomed Central 